\title{
STABILITY OF RUBBLE MOUND BREAKWATERS WITH A BERM
}

\author{
Marcel R.A. van Gent ${ }^{1}$, Gregory M. Smith ${ }^{2}$ and Ivo M. van der Werf ${ }^{3}$
}

\begin{abstract}
The stability of rock slopes with a horizontal berm has been studied by means of physical model tests. This paper is focussed on the rock slope stability of the slopes above and below the berm. By applying a berm the rock size can be reduced compared to the required rock size for a straight slope without a berm. This reduction can be significant for the slope above the berm. The influence of the slope angle (1:2 and 1:4), the width of the berm, the level of the berm, and the wave steepness have been investigated. Based on the test results prediction formulae have been derived to quantify the required rock size for rubble mound breakwaters with a berm.
\end{abstract}

Keywords: coastal structures; breakwaters; rock slopes; stability; berm; physical model tests; design formula

\section{INTRODUCTION}

For rubble mound breakwaters and dikes the presence of a berm in the seaward slope can be very effective to reduce wave overtopping. To assess the influence of a berm on the wave overtopping discharge several methods are available; these can be based on empirical formulae or based on the data-driven Neural Network technique (see e.g. Van Gent et al, 2007). A berm in the seaward slope of a rubble mound breakwater does not only reduce the wave overtopping discharge, it can also increase the stability of the rock in the armour layer. For the influence of berms on the stability only limited information is available, e.g. Vermeer (1986), the Rock Manual (2007) for a structure with a slope below the berm of 1:6, and Dijkstra (2008) provides information on the stability of the slope below and at the berm. To fill the knowledge gap for steeper slopes (steeper than 1:6, which is relevant for many practical applications) and also for the slope above the berm a new series of physical model tests have been performed. The analysis of the stability of the upper 1:2 slope tests was previously presented in Van Gent et al (2011). Here, the data set has been extended (1:2 and 1:4 slopes) and the analysis is performed for the stability of the rock material above the berm and also for the rock material below the berm. Prediction formulae have been derived for reduction factors that can be applied to the required rock size for rubble mound structures with a berm compared to straight rock slopes.

\section{PHYSICAL MODEL TESTS}

Physical model tests were performed in a wave flume (width $1 \mathrm{~m}$, height $1.2 \mathrm{~m}$, length $110 \mathrm{~m}$ of which $55 \mathrm{~m}$ was used here) at Deltares, Delft. The wave board is equipped with second-order wave steering and active reflection compensation.

Wave conditions were measured at deep water and at the location of the structure toe. The analysis was based on the time series of the incident waves at the toe. These signals, without reflected waves, were obtained using the method by Mansard and Funke (1980). The spectral significant wave height $H_{s}$ and the wave period $T_{m-1,0}\left(T_{m-1,0}=m_{-1} / m_{0}\right)$ were obtained from the measured wave energy spectra. In Van Gent (2001) the wave period $T_{m-1,0}$ was found to appropriately describe the influence of wave energy spectra on wave run-up, while in later studies this wave period was found to be the most appropriate wave period for wave overtopping, wave reflection, dune erosion, and the stability of rock slopes. (e.g. Van Gent et al, 2003). In all tests a Jonswap wave spectrum has been applied.

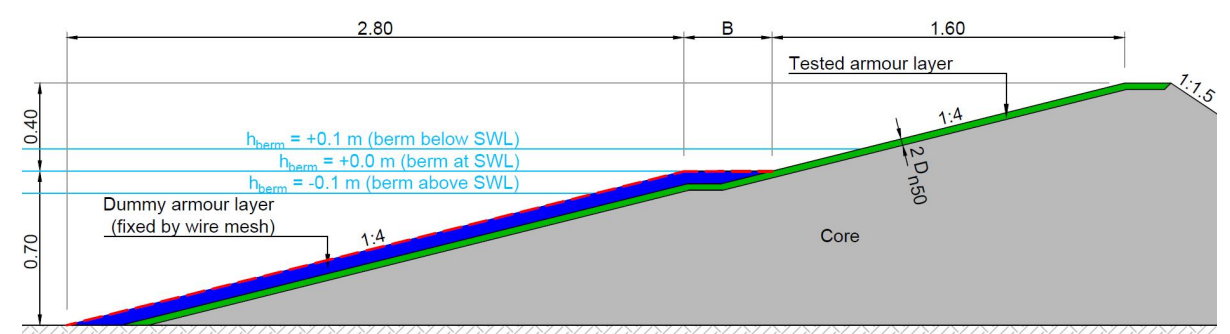

Figure 1. Configuration of tested 1:4 structure with a berm (for stability of upper slope).

\footnotetext{
${ }^{1}$ Deltares, PO Box 177, 2600 MH Delft, The Netherlands; Marcel.vanGent@Deltares.nl

2 Van Oord, PO Box 8574, 3009 AN Rotterdam, The Netherlands

${ }^{3}$ Deltares, PO Box 177, 2600 MH Delft, The Netherlands
} 
The basic configurations consist of non-overtopped rock slopes with a horizontal berm, with a 1:2 slope above and below the berm, or a 1:4 slope above and below the berm (see Figures 1 and 2). A horizontal foreshore on which no wave breaking occurred has been applied. The width and position of the berm with respect to the water level was varied. Structures with a berm width of $0 \mathrm{~m}, 0.2 \mathrm{~m}, 0.4 \mathrm{~m}$ and $0.8 \mathrm{~m}$ were tested. The still water levels (SWL) were $0.1 \mathrm{~m}$ below, at, and $0.1 \mathrm{~m}$ above the berm. For the 1:2 slopes the size of the rock in the armour layer was $D_{n 50}=20 \mathrm{~mm}$ in the upper slope and $D_{n 50}=40 \mathrm{~mm}$ in the lower slope and the berm. For the 1:4 slopes the size of the rock in the armour layer was $D_{n 50}=14 \mathrm{~mm}$ in the upper slope and $D_{n 50}=28 \mathrm{~mm}$ in the lower slope and the berm.

Damage was measured with a surface profiler consisting of 9 gauges, providing the average erosion profile and eroded area $A_{e}$. The damage levels $S=A_{e} / D_{n 50}{ }^{2}$ were mainly between $S=0$ and 20 .

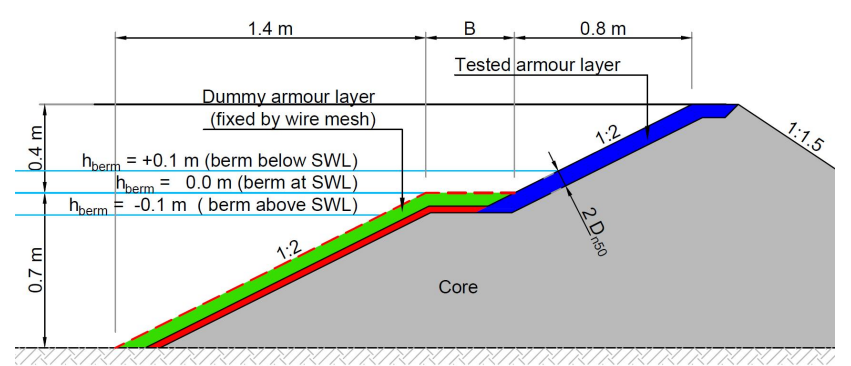

Figure 2. Configuration of tested 1:2 structure with a berm (for stability of upper slope).

Each configuration was tested with a series of test runs with an increasing wave height and a constant wave steepness. Each test run consisted of 1000 waves. The significant wave height was increased in steps of $0.02 \mathrm{~m}$ until the amount of damage in the previous test run had reached a level of $S=12$, or a maximum significant wave height of $H_{s}=0.24 \mathrm{~m}$. Damage was repaired after each series of test runs, but not after each individual test run. This means that the measured damage could be higher than if the slope would have been repaired after each individual test run. The initial movements of stones during the first test run of each series of wave heights (i.e. test run with the lowest waves) was not counted as damage but was considered to be initial settlement to a normal, settled pattern. Each configuration was tested with 2 values for the wave steepness $\left(s_{p}=0.015\right.$ and $s_{p}=0.04$ which corresponds to $s_{m-1,0}=0.018$ and $s_{m-1,0}=0.048$ respectively).

\begin{tabular}{|l|c|c|}
\hline \multicolumn{3}{|c|}{ Table 1. Parameters of the data set. } \\
\hline Parameter & Symbol & Value \\
\hline Slope angle & cot $\alpha$ & 2 and 4 \\
\hline Relative density & $\Delta$ & 1.7 \\
\hline Rock size upper slope $(\mathrm{m})$ & $D_{n 50 \text {-upper }}$ & 0.020 and 0.014 \\
\hline Rock size lower slope and berm $(\mathrm{m})$ & $D_{n 50-\text { lower }}$ & 0.040 and 0.028 \\
\hline Grading armour material & $D_{n 85} / D_{n 15}$ & 1.5 \\
\hline Core material & $D_{n 50-c o r e} / D_{n 50-\text { upper }}$ & 0.5 and 0.7 \\
\hline Berm width $(\mathrm{m})$ & $B$ & $0.0-0.8$ \\
\hline Berm level w.r.t. SWL $(\mathrm{m})$ & $h_{b}$ & $-0.1-0.1$ \\
\hline Berm level ratio (positive: submerged) & $h_{b} / H_{s}$ & $-1.2-1.4$ \\
\hline Wave steepness $\left(T_{m-1,0}\right)$ & $S_{m-1,0}$ & $0.018-0.048$ \\
\hline Wave steepness $\left(T_{p}\right)$ & $S_{p}$ & $0.015-0.040$ \\
\hline Surf-similarity parameter $\left(T_{m-1,0} ;\right.$ cot $\left.\alpha\right)$ & $\xi_{m-1,0}$ & $1.2-4.2$ \\
\hline Wave height ratio & $H_{2 \%} / H_{s}$ & 1.4 \\
\hline Deep-water wave height over depth & $H_{s} / h_{\text {toe }}$ & $<0.4$ \\
\hline Number of waves & $N$ & 1000 \\
\hline Stability parameter & $H_{s} / \Delta D_{n 50}$ & $2-8$ \\
\hline Damage level & $S$ & $<20$ \\
\hline
\end{tabular}

Tests were performed to analyse the stability of the slope above the berm, while the material at the lower slope was fixed in place with a wire mesh, and tests were performed to analyse the stability of the slope below the berm, while the material at the upper slope was fixed. In the tests for the lower slope a maximum of 4 berm widths was tested $(0 \mathrm{~m}, 0.2 \mathrm{~m}, 0.4 \mathrm{~m}$ and $0.8 \mathrm{~m})$; in the tests for the upper slope 3 berm widths were tested $(0 \mathrm{~m}, 0.2 \mathrm{~m}$ and $0.4 \mathrm{~m})$. In each test series between 2 and 7 test runs were performed. Table 1 provides an overview of the applied values of the most important parameters. 


\section{PREDICTION METHOD FOR THE UPPER SLOPE}

Based on the physical model tests prediction methods have been derived for the upper slope and for the lower slope. First, the method for the upper slope is discussed. This is an extension of the method described in Van Gent et al (2011); here the influence of the slope angle is incorporated. For a slope angle of 1:2 the method proposed here leads to the same results as the method in Van Gent et al (2011).

Here, a method with empirical formulae will be described to provide guidance in the conceptual design stage to determine the required stone size above the berm. Such a reduction in stone size facilitates important cost savings for rubble mound breakwaters with a berm. The increased stability for a structure with a berm compared to the stability of a straight slope can be quantified based on the described data set.

The proposed approach to assess the damage to the upper slope is as follows:

1. Determine the damage $S$ for a straight slope without berm using an existing stability formula.

2. Determine the damage $S_{z-b e r m}$ for a slope without berm, but only for the part of the slope that is above the vertical position of the berm: $S_{z-b e r m}=\gamma_{p o s} S$

3. Determine the reduction to the damage due to the presence of the berm:

$S_{\text {berm }}=\gamma_{\text {berm }} S_{z \text {-berm }}=\gamma_{\text {berm }} \gamma_{\text {pos }} \mathrm{S}$

1: For the first step an existing stability formula can be applied. In Van Gent et al (2003) the stability equations by Van der Meer (1988) were modified to extend its field of application. These modified equations are for plunging waves:

$$
\frac{S}{\sqrt{N}}=\left(\frac{1}{c_{\text {plunging }}} \frac{H_{s}}{\Delta D_{n 50}} \xi_{m-1,0}^{0.5} P^{-0.18} \frac{H_{2 \%}}{H_{s}}\right)^{5}
$$

and for surging waves:

$$
\frac{S}{\sqrt{N}}=\left(\frac{1}{c_{\text {surging }}} \frac{H_{s}}{\Delta D_{n 50}} \xi_{m-1,0}{ }^{-P} P^{0.13} \tan \alpha^{0.5} \frac{H_{2 \%}}{H_{s}}\right)^{5}
$$

with the transition at $\xi_{c}=\left(c_{\text {plunging }} / c_{\text {surging }} P^{0.31} \sqrt{ } \tan \alpha\right)^{1 /(P+0.5)}$. For slopes that are more gentle than $\cot \alpha=4$ the equation for plunging waves (Eq.1) needs to be used, irrespective of whether $\xi_{m-1,0}$ is larger than $\xi_{c}$ or not. The optimal values for the coefficients are $c_{\text {plunging }}=8.4$ and $c_{\text {surging }}=1.3$. For the tested structures $P=0.5$ is used.

Since the effect of berms on the expected damage or required rock diameter in the upper slope can be large, using Eqs.1 and 2 as a reference for straight slopes without a berm leads for many applications to very high damage levels for straight slopes. For instance, if the rock diameter in the upper part of the slope can be reduced with a factor 2 to 3, the calculated $S$ values for straight slopes may be about 30 to 250 times larger. This means that Eqs. 1 and 2 are often applied in the calculation method outside their range of validity. The present data is both in the range of "plunging waves" and "surging waves". However, the data on "surging waves" is close to the transition from "plunging waves" to "surging waves". Since structures with a berm can also be seen as structures that are somewhat more gentle than without a berm, such that the waves would actually be more plunging than surging, here all data is treated as "plunging waves" (i.e. only Eq.1 is applied).

2: The second step is to account for the vertical position of the berm to facilitate a comparison for configurations with and without a berm. Tests with 1:2 and 1:4 slopes were performed without a berm $(B=0)$, but with the rock in the lower part fixed and in the upper part exposed such that only damage could occur above a specific 'berm' level ( $z_{\text {berm }}$ is positive if the level of the berm is above SWL; $\left.z_{\text {berm }}=-h_{b}\right)$. Although for this step limited data is available an estimate is made to obtain an empirical formula for $\gamma_{p o s}=S_{z-b e r m} / S$. Based on the tests with the low-wave steepness and $S_{z-b e r m}<12$ an empirical formula has been derived (incorporating the slope angle unlike in Van Gent et al, 2011, but leading to the same results for 1:2 slopes):

$$
\gamma_{p o s}=\left(0.25+0.125 \cot \alpha\left(1+\frac{h_{b}}{H_{s}}\right)\right)^{5} \quad \text { with } 0 \leq \gamma_{p o s} \leq 1
$$




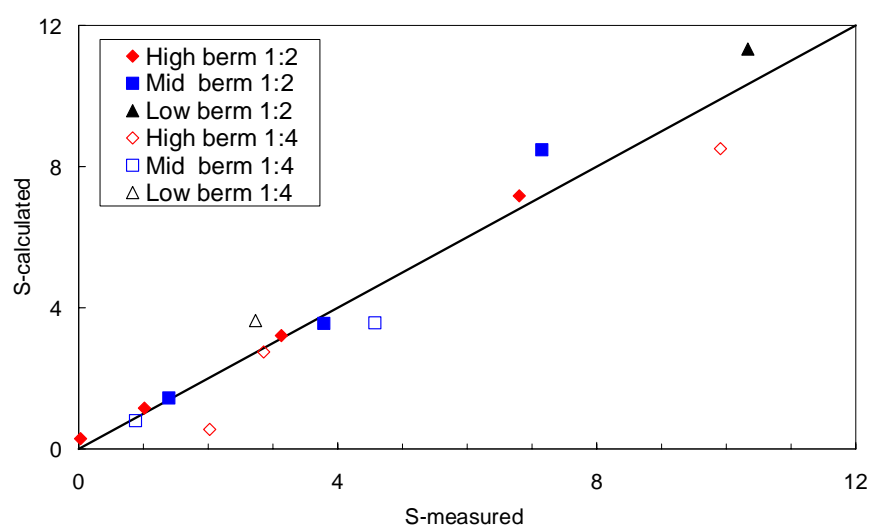

Figure 3. Calculated and measured damage on the upper part of the slope for tests with $B=0$ (Eqs.1 and 3).

For a 1:2 slope Eq.3 means that if the level of the berm would be at $2 H_{s}$ above SWL (emerged berm; $h_{b}=-2 H_{s}$ ) or higher this would lead to no damage to the upper slope: $\gamma_{p o s}=0$. For levels equal or lower than $2 H_{s}$ below (submerged berm; $h_{b}=2 H_{s}$ ) there is no reduction: $\gamma_{p o s}=1$. For the situation that the berm is at the level of the SWL, $\gamma_{p o s}=(0.5)^{5}$ which means that a diameter that is a factor 2 smaller, would lead to the same value for $S$; thus, if for instance $S=4$ would be acceptable for a straight slope, and $S=4$ would also be acceptable for the upper slope, the diameter can be a factor 2 smaller in the upper slope. However, it should be noted that if a certain damage level is considered acceptable for a straight slope, it is possible that for the upper slope a somewhat smaller damage level should be applied since part of the damage is likely to occur to the lower part of the slope. If half of the acceptable damage would be attributed to the upper slope (e.g. $S=2)$, in this example the size of the diameter in the upper slope could be reduced with a factor 1.75 (with $S=2$ ) compared to the required diameter for the entire straight slope $(S=4)$.

In this paper no detailed guidelines are given on what is an acceptable damage level for the part of the slope above the berm. However, the tests show that for all data on the upper slope with damage values lower than $S=20$ the average erosion profiles do not show erosion into the material underneath the armour layer. The average erosion profiles are the average of 9 individual profiles. For some of the conditions with damage values lower than $S=20$ the average profile shows no erosion until the layer underneath the armour layer while in one or more individual profiles the material underneath the armour layer is exposed over a section wider than two armour rock diameters. For damage values lower than $S=12$ such erosion into the material underneath the armour layer does sporadically occur in individual erosion profiles.

For a 1:4 slope wave run-up and wave run-down are less than for a 1:2 slope. Therefore, it is reasonable that for more gentle slopes the level above which no damage is expected, is lower than for steep slopes (Eq.3 leads to no damage to the upper slope for emerged berms that are higher than $2 H_{s}$ above SWL for 1:2 slopes while for 1:4 slopes this level is $1.5 H_{s}$ ).

Figure 3 shows the measured damage to the part above the level of the berm (with $B=0$ ) compared to the calculated damage using Eq.1 and Eq.3. For purpose of conceptual design the match between the measured and calculated damage is considered to be sufficient.

3: The third step is to account for the influence of the berm on the stability. The parameters that are accounted for here are the width of the berm, the wave steepness and the slope angle, the latter two combined in the surf-similarity parameter $\xi_{m-1,0}$. The following empirical formula is calibrated for the upper slope:

$$
\gamma_{\text {berm }}=1-0.15 \xi_{m-1,0}\left(\frac{B}{H_{s}}\right)^{0.3} \quad \text { with } \gamma_{b e r m} \geq 0
$$

The resulting stability formula can be written as follows (for the upper slope):

$$
S=\gamma_{\text {berm }} \gamma_{\text {pos }}\left(\frac{1}{c_{\text {plunging }}} \frac{H_{s}}{\Delta D_{n 50}} \xi_{m-1,0}^{0.5} P^{-0.18} N^{0.1} \frac{H_{2 \%}}{H_{s}}\right)^{5}
$$




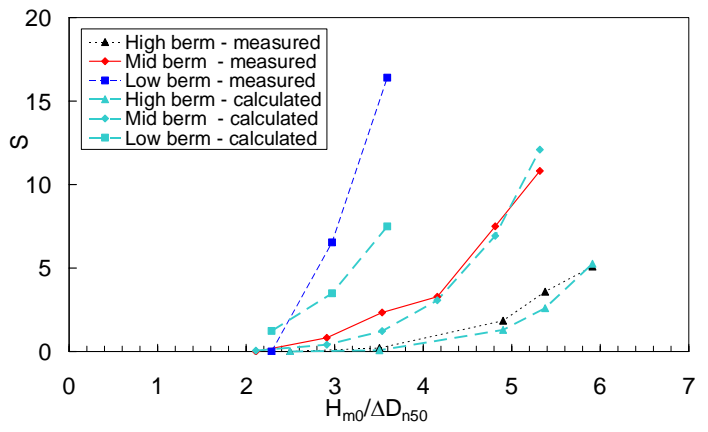

a) Narrow berm and low wave steepness

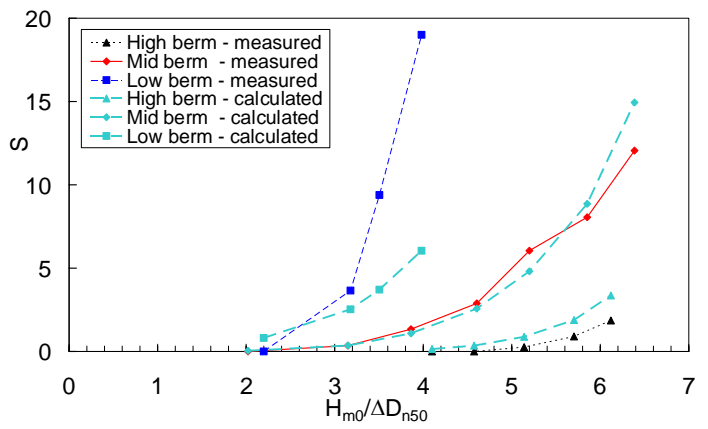

c) Narrow berm and high wave steepness

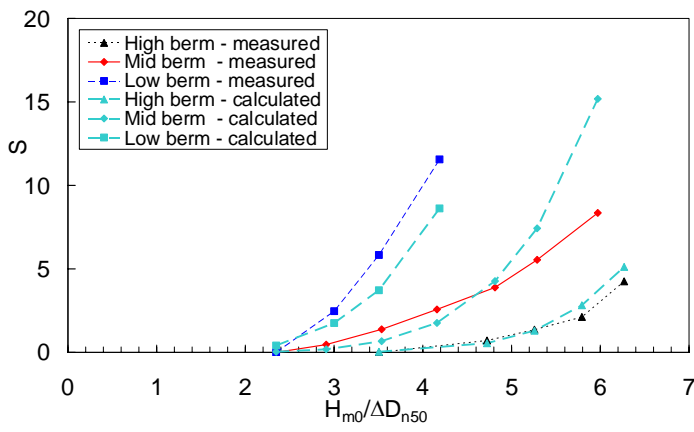

b) Wide berm and low wave steepness

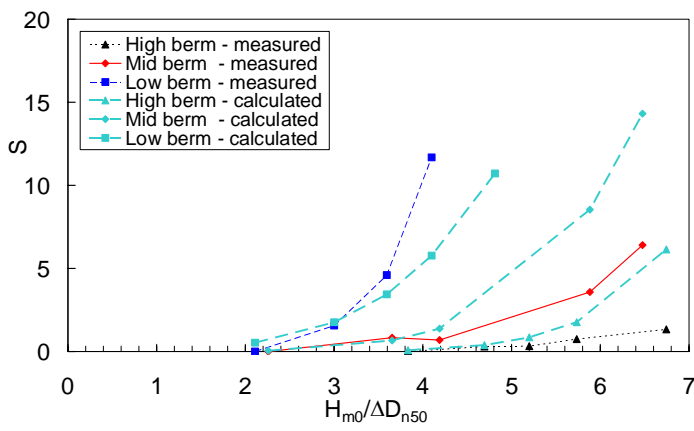

d) Wide berm and high wave steepness

Figure 4. Measured and calculated damage levels for the upper slope (1:2 slopes).

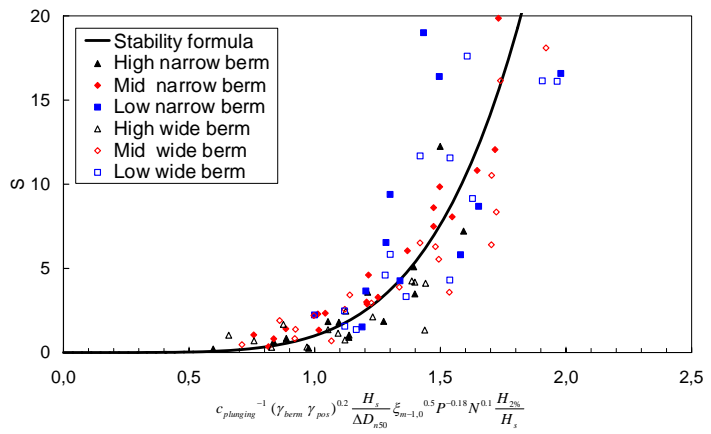

a) High (emerged), mid and low (submerged) berms

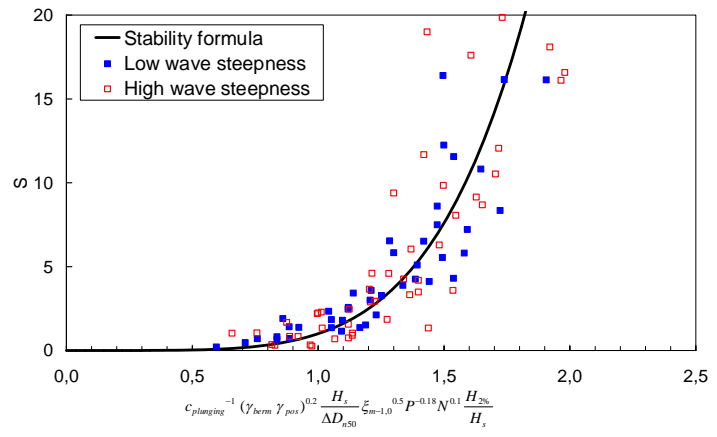

c) Low and high wave steepness

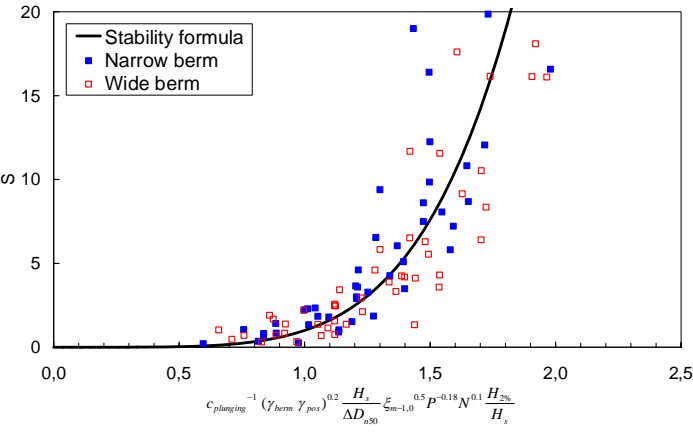

b) Narrow and wide berms

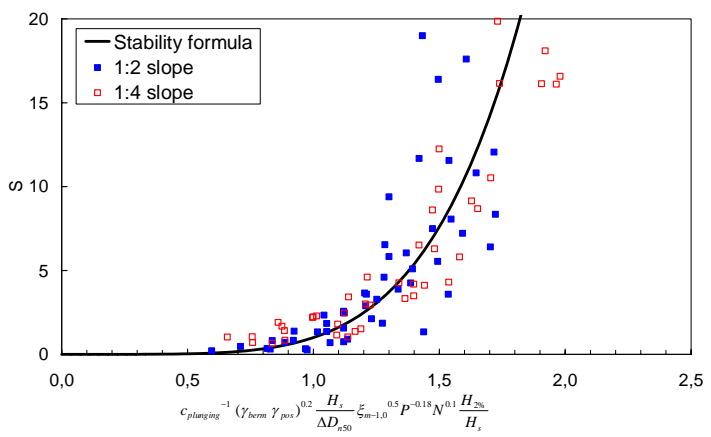

d) $1: 2$ and $1: 4$ slopes

Figure 5. Measured damage levels versus prediction formula for the upper slope; dependency parameters. 
Figure 4 shows measured and calculated damage levels, each for the 3 levels of the berm (1:2 slope). The results of the measurements show:

- A wider berm leads to less damage.

- A higher berm leads to less damage; for low berms the damage increases relatively quickly with increasing wave heights, while for a high berm the damage progresses more gradually.

- A higher wave steepness leads to less damage.

The comparison between measured and calculated damage levels shows (see also Figure 4 for 1:2 slopes and Figure 5 for all data):

- The agreement between measured and calculated damage is rather good. The standard deviation of the differences between measured and predicted values of $S / \sqrt{ } N$ is 0.12 for all data with $S$ smaller than 20 and 0.07 for all data with $S$ smaller than 12. Note that the standard deviation for data with straight slopes as described in Van Gent et al (2003) and Van Gent (2004) was 0.10 for rock slopes with a permeable core.

- The calculated and measured values show similar trends for the level of the berm, for the width of the berm, for the wave steepness, and for the slope angle.

- The agreement between measured and calculated damage is similar for the narrow and wide berms.

- The agreement between measured and calculated damage is somewhat better for the low wave steepness than for the high wave steepness

- The agreement between measured and calculated damage is similar for 1:2 and 1:4 slopes; the influence of a berm is more significant in combination with a steep slope than for a gentle slope.

\section{Sensitivity to applied formula for straight slopes}

In Van Gent et al (2011) the influence of using Eq.1 only ("plunging waves") instead of using both Eqs.1 and 2 ("plunging and surging waves") has been analysed and found to be hardly of any influence.

The measured damage levels were the result of a number of conditions, thus representing cumulative damage. In the analysis each condition has been treated as an individual storm without preceding conditions. Also this aspect was found not to be essential for the prediction formulae.

Here, in the first step the modified version of the formulae by Van der Meer (1988), as proposed in Van Gent et al (2003), has been used (Eq.1). In the latter also a more simple formula was proposed that can be applied, for instance if no information on the wave period or wave energy spectra is available. If no information on the wave period is available also Eq.4 needs to be simplified since the wave steepness is present in this formula. This leads to:

$$
\gamma_{\text {berm }}=1-(\cot \alpha)^{-1}\left(\frac{B}{H_{s}}\right)^{0.3} \quad \text { with } \gamma_{b e r m} \geq 0
$$

This leads to the following simplified formula for the stability of rock in the upper slope:

$$
S=\gamma_{b e r m} \gamma_{p o s}\left(0.57 \frac{H_{s}}{\Delta D_{n 50}}(\tan \alpha)^{0.5}\left(1+D_{n 50 c o r e} / D_{n 50}\right)^{-2 / 3} N^{0.1}\right)^{5}
$$

Using this formula (Eqs.3, 6 and 7) leads to a standard deviation of the differences between measured and predicted values of $S / \sqrt{ } N$ of 0.14 for all data with $S$ smaller than 20 and 0.08 for all data with $S$ smaller than 12. Both are slightly larger than using Eqs.3, 4 and 5.

\section{Application of prediction method for upper slope}

Applying the prediction method for the upper slope as given in Eqs. 3 to 5, Figure 6 shows graphs where on the vertical axis the increase of stability is shown by using the ratio of required rock size for a straight slope and the required rock size above the berm. This figure shows this ratio as a function of the (non-dimensional) water depth above the berm $\left(h_{b} / H_{s}\right)$ where positive values denote submerged berms and negative values denote emerged berms. In Figure 6 a ratio of for instance 2.5 means that at the upper slope a rock diameter can be applied that is a factor 2.5 smaller than for a straight slope under the same wave loading, accepting the same damage level for the upper slope as for the straight slope. 


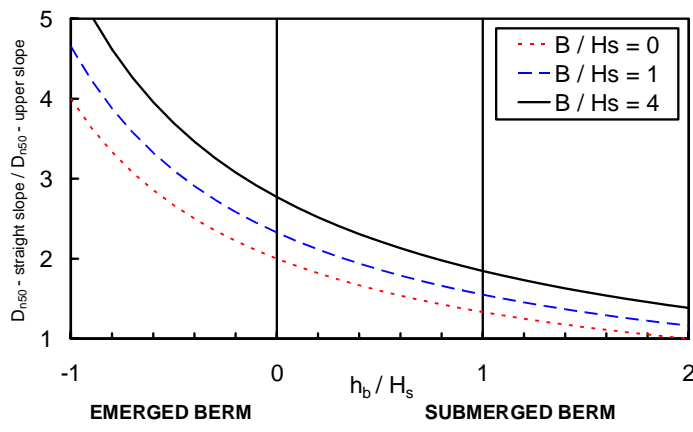

a) Berm width (1:2 and $\left.s_{m-1,0}=0.02\right)$

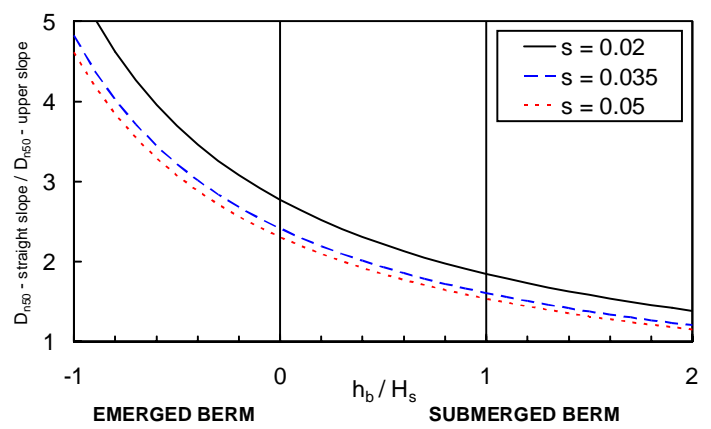

c) Wave steepness (1:2 and $\left.B / H_{s}=4\right)$

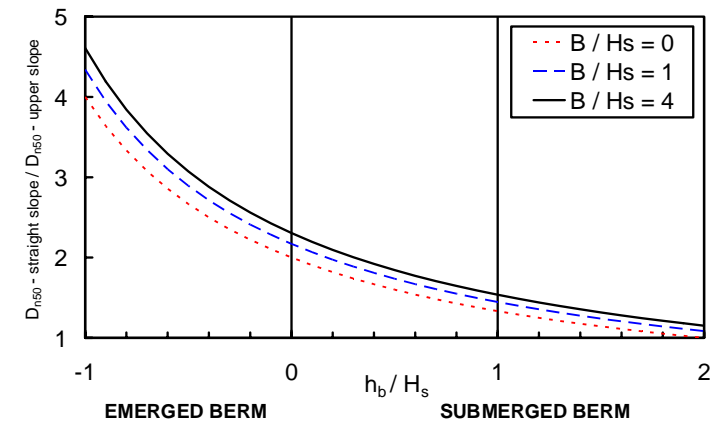

b) Berm width (1:2 and $\left.s_{m-1,0}=0.05\right)$

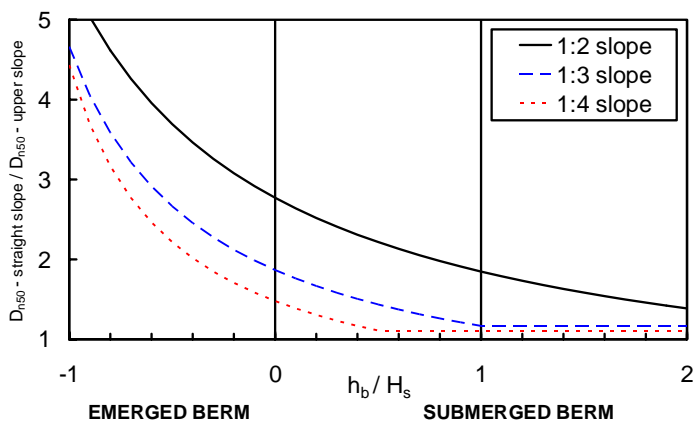

d) Slope angle $\left(s_{m-1,0}=0.02\right.$ and $\left.B / H_{s}=4\right)$

Figure 6. Stability increase in terms of required rock size in the upper slope compared to straight slopes, applying the prediction formula (Eqs. 3-5).

Figure 6 indicates that for a low (submerged) berm the reduction in required rock size is small, for a berm at SWL the reduction is large and for a high berm the reduction is very large. The upper left panel (a) shows that the influence of the berm width is important, especially in combination with a low wave steepness (compare to the upper right panel, which is for a high wave steepness). The lower left panel (c) shows the influence of the wave steepness; this example indicates that the wave steepness is somewhat less important than the berm width and the slope angle. The lower right panel (d) shows the influence of the slope angle. The latter clearly shows that for steep slopes the increase in stability for configurations with a berm is much larger than for more gentle slopes with a berm.

In the Rock Manual (2007) Fig.5.69 shows a diagram for an upper slope of 1:3 in combination with a 1:6 lower slope. At $h_{b} / H_{s}=1$ the diagram shows an increase in stability of about 1.75 , which is a higher reduction factor than the value shown in Figure $6 \mathrm{~d}$ (about 1.2) for a 1:3 slope below and above the berm (for comparison $B / H_{s}=4$ corresponds to about $B / L=0.1$ ).

Within the ranges of parameters shown in Table 1, Eqs.3 to 5 (illustrated by Figure 6) can be used as a guideline for the conceptual design of rock slopes above a horizontal berm.

\section{PREDICTION METHOD FOR THE LOWER SLOPE}

Based on the physical model tests prediction methods have been derived for the upper slope and for the lower slope. Now, the method for the lower slope is discussed. Actually, the measured damage levels include also damage to the berm itself; often damage occurs at the transition from the lower slope to the berm such that a clear distinction between damage to the lower slope and damage to the berm cannot be made.

For the prediction of damage to the lower slope a more simple approach is applied than for the damage to the upper slope, namely using Eq.5 with $\gamma_{\text {pos }}=1$ and deriving expressions for $\gamma_{\text {berm }}$ including the influence of the level of the berm.

In Figure 7a the measured damage to the lower slope is shown for structures with the berm at the still water level (SWL). It shows that there is no reduction in the damage due to the berm $\left(\gamma_{\text {berm }}=1\right)$ for $h_{b}=0$. For submerged and emerged berms there is a reduction in the damage due to the berm. 


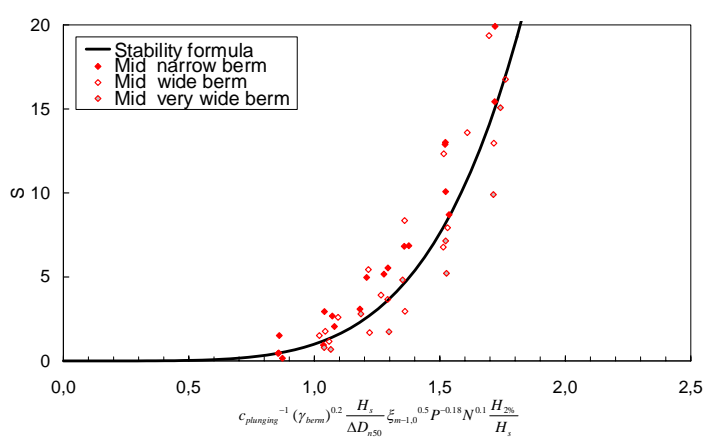

a) Berms at SWL $\left(h_{b} / H_{s}=0\right): \gamma_{b e r m}=1$

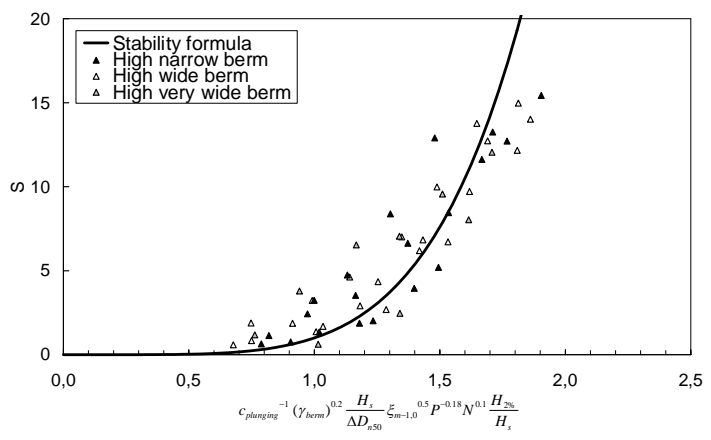

c) Emerged berms $\left(h_{b} / H_{s}<0\right)$

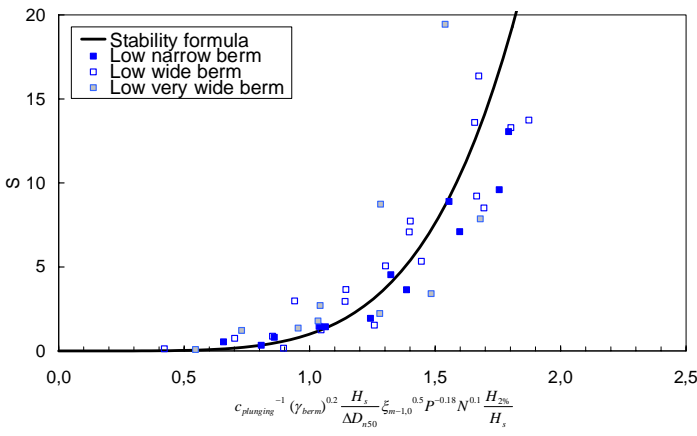

b) Submerged berms $\left(h_{b} / H_{s}>0\right)$

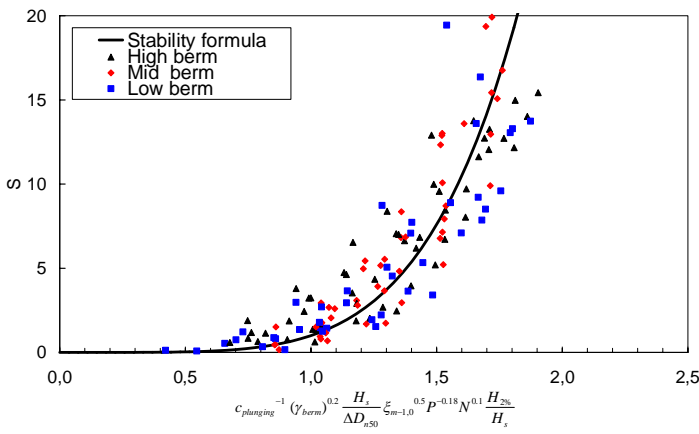

d) All berm levels

Figure 7. Measured damage levels versus prediction formula for the lower slope; dependency berm level.

For submerged berms the reduction in damage levels to the lower slope depends on the level of the berm $\left(h_{b} / H_{s}\right)$ and the width of the berm $\left(B / H_{s}\right)$. No clear influence of the wave steepness or the slope angle could be observed for submerged berms. The calibrated expression for submerged berms reads:

$$
\gamma_{\text {berm }}=1-0.12 \frac{B}{H_{s}} \frac{h_{b}}{H_{s}} \quad \text { with } \quad h_{b} / H_{s} \geq 0
$$

Figure $7 \mathrm{~b}$ shows measured and calculated damage to the lower slope for submerged berms, using Eq.8 in combination with Eq.5.

For emerged berms the reduction in damage levels to the lower slope depends on the level of the berm $\left(h_{b} / H_{s}\right)$, the width of the berm $\left(B / H_{s}\right)$, the wave steepness, and the slope angle, the latter two combined in the surf-similarity parameter $\xi_{m-1,0}$. The calibrated expression for emerged berms reads:

$$
\gamma_{\text {berm }}=1-0.02 \xi_{m-1,0} \frac{B}{H_{s}}\left|\frac{h_{b}}{H_{s}}\right| \quad \text { with } \quad h_{b} / H_{s} \leq 0
$$

Figure $7 \mathrm{c}$ shows measured and calculated damage to the lower slope for emerged berms, using Eq.9 in combination with Eq.5.

Figure $7 \mathrm{~d}$ shows measured and calculated damage to the lower slope for all berm configurations. The comparison between measured and calculated damage levels to the lower slope shows (see Figures 7 and 8):

- The agreement between measured and calculated damage is rather good. The standard deviation of the differences between measured and predicted values of $S / \sqrt{ } N$ is 0.09 for all data with $S$ smaller than 20 and 0.06 for all data with $S$ smaller than 12 . Note that for the lower slope also tests were performed with a very wide berm, wider than those used for the upper slope. Nevertheless, the accuracy of the prediction method (Eqs.5, 8 and 9) is more accurate than for the upper slope. 


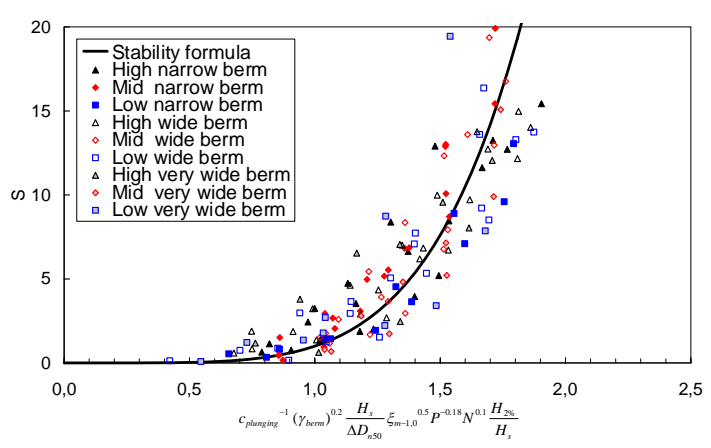

a) High (emerged), mid and low (submerged) berms

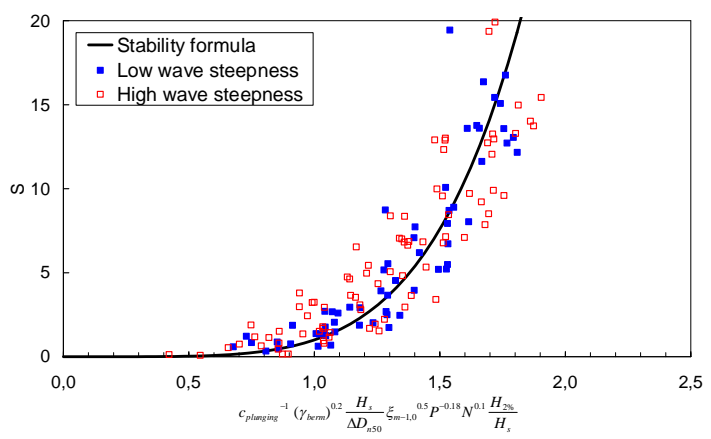

c) Low and high wave steepness

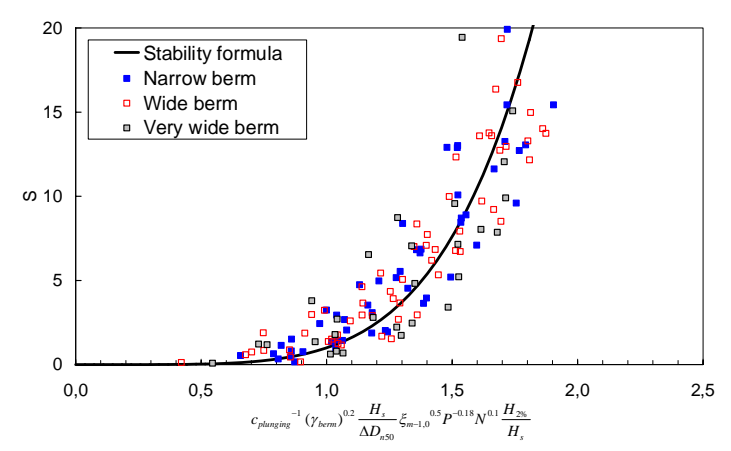

b) Narrow, wide and very wide berms

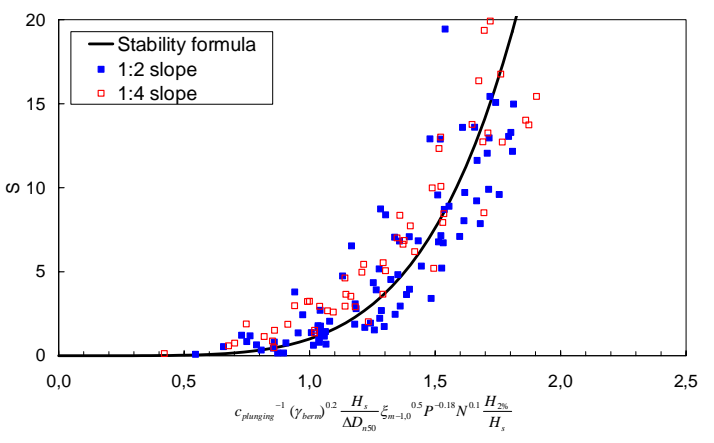

d) $1: 2$ and 1:4 slopes

Figure 8. Measured damage levels versus prediction formula for the lower slope; dependency parameters.

- The agreement between measured and calculated damage is somewhat better for the narrow and wide berms $\left(0 \leq B / H_{s} \leq 4\right)$ than for the very wide berms $\left(4<B / H_{s} \leq 8\right)$.

- The agreement between measured and calculated damage is somewhat better for the low wave steepness than for the high wave steepness.

- The agreement between measured and calculated damage is similar for 1:2 and 1:4 slopes; the influence of an emerged berm is more significant in combination with a steep slope than for a gentle slope.

In this paper no detailed guidelines are given on what is an acceptable damage level for the part of the slope below the berm. However, the tests show that for all data on the lower slope with damage values lower than $S=20$ the average erosion profiles do not show erosion into the material underneath the armour layer. The average erosion profiles are the average of 9 individual profiles. For some of the conditions with damage values lower than $S=20$ the average profile shows no erosion until the layer underneath the armour layer while in one or more individual profiles the material underneath the armour layer is exposed over a section wider than two armour rock diameters. For damage values lower than $S=12$ such erosion into the material underneath the armour layer does not occur in individual erosion profiles.

\section{Sensitivity to applied formula for straight slopes}

Here, in the first step the modified version of the formulae by Van der Meer (1988), as proposed in Van Gent et al (2003), has been used (Eq.1). In the latter also a more simple formula was proposed that can be applied, for instance if no information on the wave period or wave energy spectra is available. If no information on the wave period is available also Eq.9 for emerged berms needs to be simplified since the wave steepness is present in this formula. This leads to:

$$
\gamma_{\text {berm }}=1-0.1(\cot \alpha)^{-1} \frac{B}{H_{s}}\left|\frac{h_{b}}{H_{s}}\right| \quad \text { with } \quad h_{b} / H_{s} \leq 0
$$


This leads to the following simplified formula for the stability of rock in the lower slope:

$$
S=\gamma_{\text {berm }}\left(0.57 \frac{H_{s}}{\Delta D_{n 50}}(\tan \alpha)^{0.5}\left(1+D_{n 50 \text { core }} / D_{n 50}\right)^{-2 / 3} N^{0.1}\right)^{5}
$$

This formula can be used in combination with Eq. 8 for submerged berms and Eq.10 for emerged berms. Using this formula leads to a standard deviation of the differences between measured and predicted values of $S / \sqrt{ } N$ of 0.13 for all data with $S$ smaller than 20 and 0.09 for all data with $S$ smaller than 12. Both are larger than using Eqs.5, 8 and 9 for the lower slope, but similar to the accuracy of Eqs.3, 6 and 7 for the upper slope.

\section{Application of prediction method for lower slope}

Applying the prediction method for the lower slope as given in Eqs.5, 8 and 9, Figure 9 shows graphs where on the vertical axis the increase of stability is shown by using the ratio of required rock size for a straight slope and the required rock size below the berm. This figure shows this ratio as a function of the (non-dimensional) water depth above the berm $\left(h_{b} / H_{s}\right)$ where positive values denote submerged berms and negative values denote emerged berms.

Figure 9 shows that the Eqs.5, 8 and 9 predict no reduction in required rock size on the lower slope for a berm at SWL. For submerged berms the reduction is more significant for lower berms and more significant for wider berms; the wave steepness and slope angle have no influence on the reduction in required rock size. For emerged berms the reduction in required rock size is more significant for higher berms and more significant for wider berms; also the wave steepness and slope angle have an influence on the reduction. It is expected that for higher berm levels the wave loading on the lower berm and the berm itself is reduced due to a reduced amount of water in the wave rundown; a larger amount of water flows downward through the permeable structure rather than along the slope, which apparently has a stabilising effect.

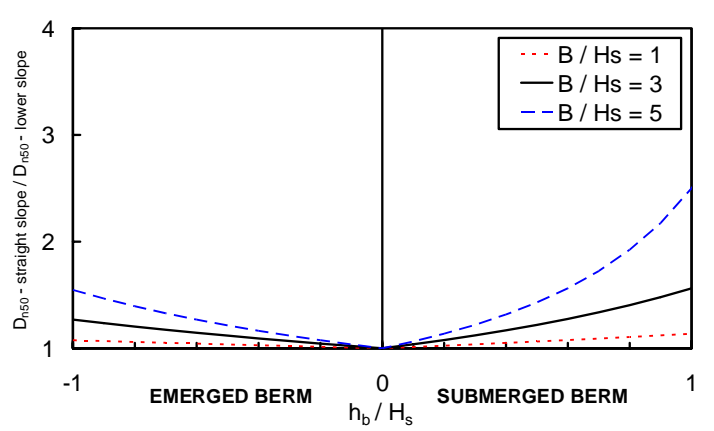

a) Berm width $\left(1: 2\right.$ and $\left.s_{m-1,0}=0.02\right)$

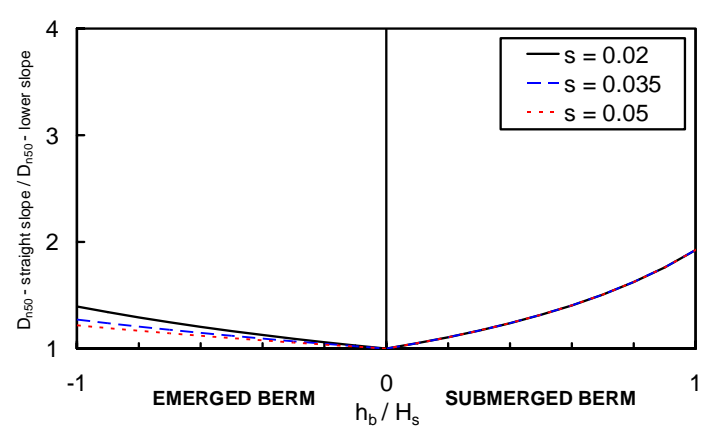

c) Wave steepness (1:2 and $\left.B / H_{s}=4\right)$

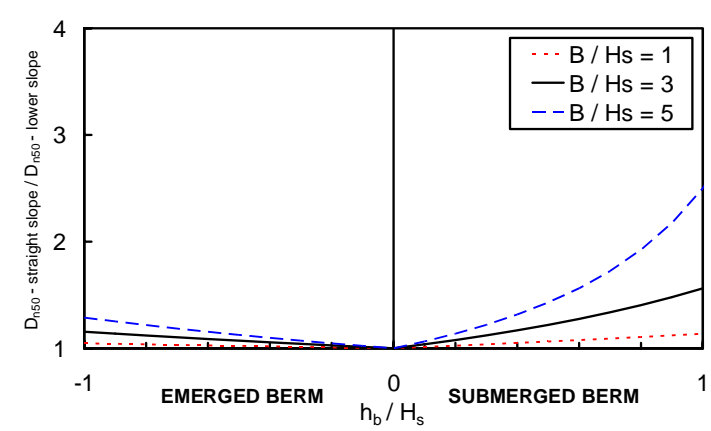

b) Berm width (1:2 and $\left.s_{m-1,0}=0.05\right)$

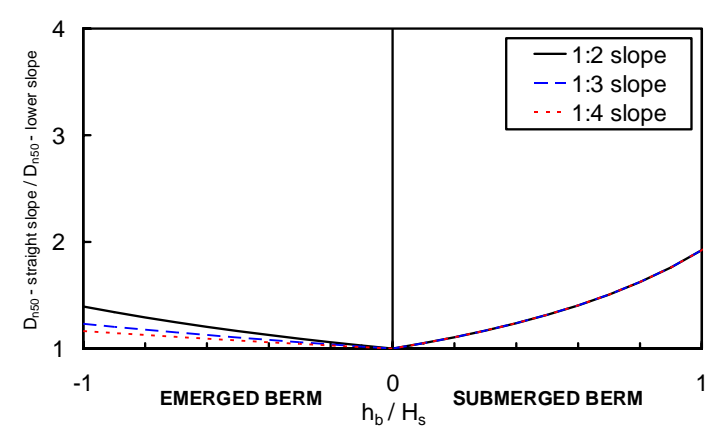

d) Slope angle $\left(s_{m-1,0}=0.02\right.$ and $\left.B / H_{s}=4\right)$

Figure 9. Stability increase in terms of required rock size in the lower slope compared to straight slopes, applying the prediction formula (Eqs. 5, 8 and 9). 
Comparing Figure 6 and Figure 9 illustrates that for emerged berms the reduction in required rock size can be much more significant for the upper slope than for the lower slope (in these examples up to about 4 to 5 for $h_{b} / H_{s}=-1$ for the upper slope and up to about 1 to 1.5 for the lower slope). For submerged berms the differences are less (in these examples up to about 1 to 2 for $h_{b} / H_{s}=1$ in the upper slope and up to about 1 to 2.5 in the lower slope).

Damage to the lower slope often occurs around the transition from the lower slope to the berm. It may therefore be advantageous to introduce mitigating measures in that localised part of the profile. It is advisable to consider to round off this transition rather than a sharp transition, in order to reduce the exposure of stones at this transition. A rounded transition may reduce also the wave reflection but may also increase the wave loading to the upper slope somewhat. Combinations of concrete units such as cubes in the lower slope and rock in the upper slope have not been studied here, but especially if a single layer of cubes is being applied in the lower slope and in the berm, while rock is being applied in the upper slope, rounding off of the transition may significantly increase the stability of the cubes.

Here, the same rock material was applied in the lower slope and in the berm. The required rock material at the transition from the berm to the lower slope and the first part of the berm is determined from Eqs.5, 8 and 9, but at positions on the berm closer to the upper slope smaller material may be sufficient.

\section{CONCLUSIONS AND RECOMMENDATIONS}

This study on the stability of rubble mound structures with a berm has lead to the following conclusions:

\section{Upper slope}

- The rock size in the upper slope, i.e. the slope above the berm, can be significantly smaller than for a straight slope without a berm.

- The increase in stability of the rock in the upper slope depends on the level of the berm, the width of the berm, the wave steepness, and the slope angle, the latter two combined in the surfsimilarity parameter $\xi_{m-1,0}$.

- The influence of a berm is more significant in combination with a steep slope than in combination with a gentle slope.

\section{Lower slope}

- There is no reduction in the damage to the lower slope and the berm itself for a berm at the stillwater level. For submerged and emerged berms there is a reduction in the damage level at the lower slope and the berm itself, compared to straight slopes. This is expected to be caused by the influence of the berm on the wave run-down.

- For submerged berms the reduction in damage levels to the lower slope depends on the level of the berm and the width of the berm. No clear influence of the wave steepness or the slope angle could be observed for submerged berms.

- For emerged berms the reduction in damage levels to the lower slope depends on the level of the berm, the width of the berm, the wave steepness, and the slope angle, the latter two combined in the surf-similarity parameter $\xi_{m-1,0}$.

- The influence of an emerged berm is more significant in combination with a steep slope than in combination with a gentle slope.

\section{Prediction method}

A prediction method, summarised in Box 1, is proposed to estimate the increase in stability for structures with a berm. Within the ranges of parameters shown in Table 1, this method can be used as a guideline for the conceptual design of rubble mound structures with rock slopes and a horizontal berm.

\section{Recommendations}

Further optimisation of rubble mound structures with a berm may be achieved by analysing at which location on the berm smaller material can be applied in the berm.

It is recommended to also study the influence of a berm on the stability of rock in the upper slope for structures with concrete armour units in the lower slope and berm. This can be relevant for cubes in a single layer in the lower slope and the berm, in combination with rock in the upper slope. 


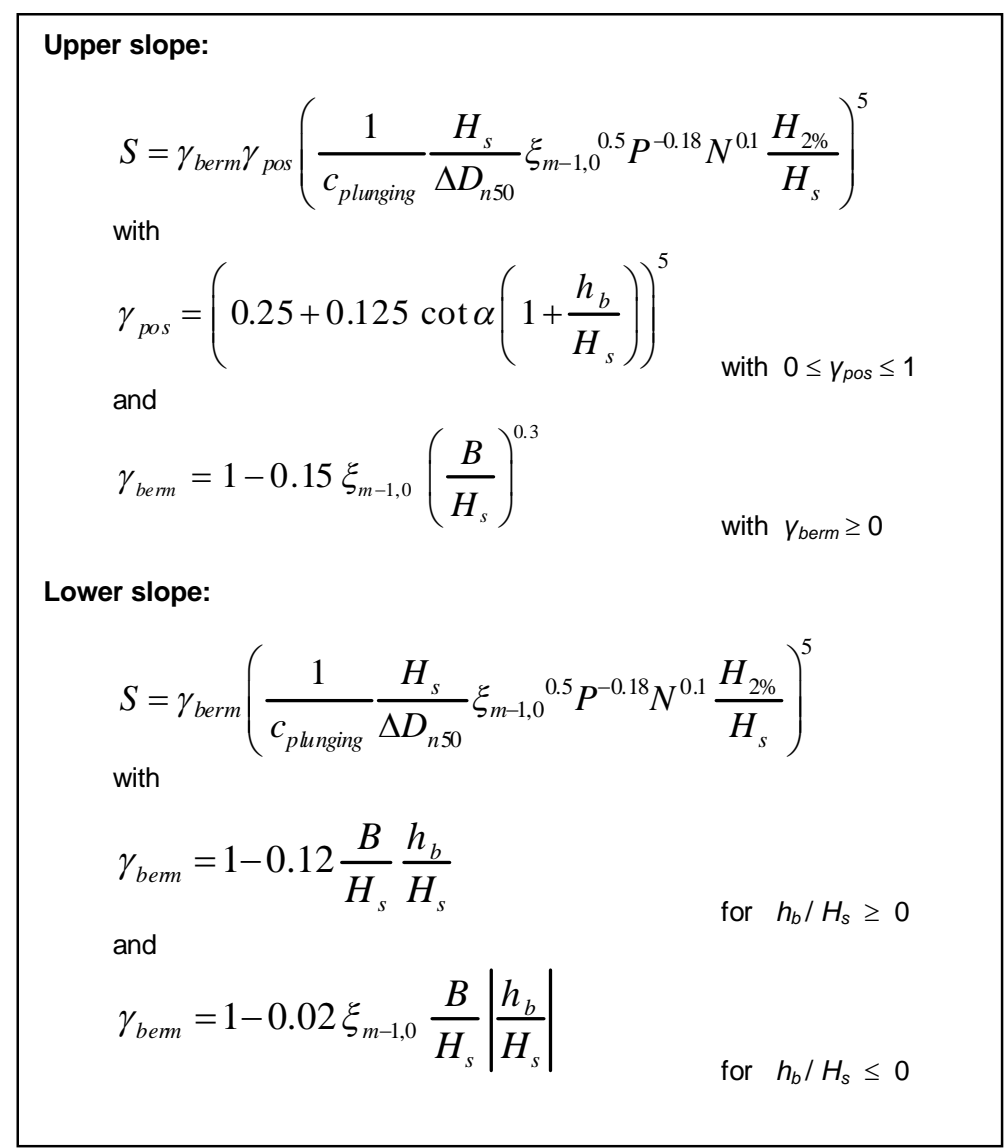

Box.1. Summary of prediction method (within the ranges given in Table 1).

\section{REFERENCES}

Dijkstra , O.P.J. 2008. Armour stability on a bermed slope breakwater, M.Sc. thesis, Delft University of Technology.

Mansard, E. and E. Funke. 1980. The measurement of incident and reflected spectra using a leastsquare method, Proc. ICCE'80, ASCE, pp.154-172.

Rock Manual. 2007. The use of rock in hydraulic engineering ( $2^{\text {nd }}$ edition), CIRIA, CUR, CETMEF, Published by C683, CIRIA, London (ISBN 978-0-86017-683-1 and 5).

Van der Meer, J.W. 1988. Rock slopes and gravel beaches under wave attack, Ph.D. thesis, Delft University of Technology.

Van Gent, M.R.A. 2001. Wave run-up on dikes with shallow foreshores, Journal of Waterway, Port, Coastal and Ocean Engineering, ASCE, Vol.127, No.5, Sept/Oct 2001, pp.254-262.

Van Gent, M.R.A., H.F.P. Van den Boogaard, B. Pozueta and J.R. Medina. 2007. Neural network modelling of wave overtopping at coastal structures, Coastal Engineering, Elsevier, Vol.54, pp. 586-593.

Van Gent, M.R.A., A. Smale and C. Kuiper. 2003. Stability of rock slopes with shallow foreshores, Proc. Coastal Structures conference 2003, Portland, USA.

Van Gent, M.R.A. 2004. On the stability of rock slopes, Balkema, Keynote, Proc. NATO-Workshop on Environmental friendly coastal protection structures, Varna, Bulgaria.

Van Gent, M.R.A., G.M. Smith and I.M. Van der Werf. 2011. Stability of rock slopes with a berm: The upper slope, Proc. Coastal Structures conference 2011, Yokohama, Japan.

Vermeer, A.C.M. 1986. Stability of rubble mound berms and toe constructions; report on literature survey and model investigation (in Dutch), Delft Hydraulics Report M2006, Delft. 